\title{
Proteomic applications of surface plasmon resonance biosensors: analysis of protein arrays
}

\author{
Jong Seol Yuk ${ }^{1}$ and Kwon-Soo $\mathrm{Ha}^{1,2}$ \\ ${ }^{1}$ Department of Molecular and Cellular Biochemistry \\ Nano-bio Sensor Research Center \\ Kangwon National University School of Medicine \\ Chunchon, Kangwon-do 200-701, South Korea \\ ${ }^{2}$ Coressponding author: Tel, 82-33-250-8833; \\ Fax, 82-33-250-8807; E-mail, ksha@kangwon.ac.kr
}

Accepted 4 February 2005

Abbreviations: AFM, atomic force microscopy; MALDI, matrixassisted laser desorption/ionization; SELDI, surface-enhanced laser desorption/ionization; SPR, surface plasmon resonance

\begin{abstract}
Proteomics is one of the most important issues in the post-genomic area, because it can greatly contribute to identifying protein biomarkers for disease diagnosis and drug screening. Protein array is a key technology for proteome researches and has been analyzed by various methods including fluorescence, mass spectrometry, atomic force microscopy and surface plasmon resonance (SPR). SPR biosensor is a promising technology in proteomics, since it has various advantages including real-time measurement of biomolecular interactions without labeling and the simple optical system for the device. SPR biosensors have a strong potential for analyzing proteomes by SPR imaging and SPR spectroscopic imaging, even though the challenge is to produce proteins on a proteomic scale.
\end{abstract}

Keywords: biosensing techniques; microscopy, atomic force; protein array analysis; proteome; proteomics; surface plasmon resonance

\section{Introduction}

Recently, intensive efforts have been put into the field of proteomics to utilize its great potential in identifying protein biomarkers for disease diagnosis and drug screening. There has been a great demand for developing efficient protein arrays, since the technology allows the large-scale and high-throughput analysis of proteomes in cells, tissues and organisms
(Zhu and Snyder, 2003). Several techniques for the analysis of protein interactions on protein arrays have been reported based on various methods such as fluorescence detection, surface-enhanced laser desorption/ionization (SELDI) mass spectrometry, atomic force microscopy (AFM), and surface plasmon resonance (SPR).

SPR has been used as an optical detection technology since Lidberg et al. (1983) demonstrated its potential to use as biosensors in 1983 (Yuk et al., 2004a). SPR-based biosensors have several advantages in the analysis of protein interactions compared to other sensors. SPR spectroscopy allows real-time measurement of biomolecular interactions without labeling and with simple optical system device (Zhu and Snyder, 2003). There are several examples in which SPR biosensors have been used to characterize the details of biomolecular interactions, and thus the SPR biosensors have emerged as one of the most powerful tools in biochemical and proteomics researches (Myszka and Rich, 2000). The success of SPR biosensors was indicated by the growing number of commercially available instruments. Since Biacore $A B$ (originally Pharmacia Biosensor $A B$ ) launched the first commercial SPR biosensor on market in 1990, there have been many more competing SPR instruments including IASys (Affinity Sensors), SPR-670 (Nippon Laser Electronics), IBIS (IBIS Technology BV), TISPR (Texas Instruments), etc. (see Table 1). The general versatility of SPR methods, the ease of automation, and the lack of labeling requirements are able to permit the potential use of the SPR biosensors for large-scale screening of proteins (McDonnell, 2001). In this review, we will discuss trends in protein array technology and a potential use of SPR biosensors in proteome researches.

\section{Significance of protein arrays in proteome analysis}

One of the urgent scientific pursuit of the post-human genome era is the understanding of gene-expressed proteins and their target reactions to distinguish functional specificity and preferences in the multi-milieu pots of proteins in the cell enclosure. Proteomics, the large-scale analysis of proteins, can provide protein biomarkers for disease diagnosis and drug screening by quantitative analysis of cellular protein expression level and protein-protein interactions in signaling networks of cells. Extensive studies on various human proteome reported include human plasma proteome (Anderson and Anderson, 2002), human liver (Yan et al., 2004), human lung fibroblasts (Durr et al., 2004), cancers (Simpson and Dorow, 2001), diseases (Ha- 
Table 1. Various commercial SPR biosensors.

\begin{tabular}{lll}
\hline \multicolumn{1}{c}{ System } & \multicolumn{1}{c}{ Manufacturer } & \multicolumn{1}{c}{ Website } \\
\hline BIACORE & BIAcore AB (Sweden) & www.biacore.com \\
TI-SPR & Texas Instruments (TX) & www.ti.com/spreeta \\
Kinetics Instrument & BioTuL Bio Instruments (Germany) & www.biotul.com \\
IASys & Affinity Sensors & www.affinity-sensors.com \\
SPR-670 & Nippon Laser Electronics (Japan) & www.rikei.com \\
IBIS & IBIS Technology BV (Netherlands) & www.ibis-spr.nl \\
OWLS & Artificial Sensing Instruments (Switzerland) & www.microvacuum.com \\
PWR-400 & Aviv (NJ) & www.avivinst.com \\
FasTraQ & Quantech Ltd (MN) & www.quantechltd.com \\
FT-SPR 100 & GWC Technologies (WI) & www.gwcinstruments.com \\
\hline
\end{tabular}

nash, 2003), etc. The human plasma proteome can provide a revolutionary tool in disease diagnosis and therapeutic monitoring, since plasma is the primary clinical specimen and represents the largest version of human proteome (Anderson and Anderson, 2002). The plasma, circulating body fluid, contains abundance of tissue origin proteins that have been released and could be used as protein markers along with a large number of immunoglobulins pools. Recently, Giot et al. (2004) has reported a protein interaction map in Drosophila melanogaster based on Yeast twohybrid method and this map can be a systems biology model for multicellular organisms including humans. They isolated 10,623 predicted transcripts and screened 4,679 proteins and 4,780 interactions by a computational method of rating two-hybrid interaction confidence map.

Proteomics has used techniques such as two-dimensional gel electrophoresis or chromatography, combined with mass spectrometry, to separate and identify proteins on a large scale (Gershon, 2003; Hanash, 2003). Mass spectrometry has been a key technology to identify and quantify a large number of proteins from complex samples, and four types of mass spectrometry such as ion trap, time-of-flight, quadrupole and Fourier transform ion cyclotron are currently in use. Mass spectrometry has been successfully applied to the study of protein-protein interactions via affinity-based isolations on a small and proteome-wide scale, the mapping of numerous organelles, description of malaria parasite proteome and quantitative protein profiling from several species (see review by Aebersold and Mann, 2003).

A quite different approach to monitor activity and function of proteome is the protein array method. Protein arrays permit a rapid interaction of proteins on a proteomic scale, and are produced by anchoring hundreds of proteins or peptides to the solid surface as a bait to capture a specific interacting proteins (Tyers and Mann, 2003). Recently, many laboratories and proteomics companies have intensively focused on the identification of a novel protein(s) and peptide biomarkers whose expression is related to the particular diseases. Based on the new biomarkers, protein arrays can provide a powerful tool to diagnose numerous diseases including cancer, arthritis, or heart disease, by a drop of a patient's blood or urine. Beyond diagnosis, protein arrays allow researchers to reveal the network of protein interactions and biochemical communication in different cells. In addition, the arrays can provide methods to illuminate expression profile of proteins at a given place and time in cells, and to screen drugs by investigating whether test compounds interact with particular proteins on the arrays.

\section{Trends in protein array technology}

\section{Analysis of protein arrays}

Protein arrays are prepared by the similar way to DNA arrays in many cases (Service, 2001). Adaptor molecules bind to specific target proteins, including proteins, antibodies, peptides, oligonucleotides or aptamers, are arrayed on a solid support, such as glass or plastic. Then, target proteins binding to adaptor molecules on the arrays are detected by various methods, such as fluorescence detection, mass spectrometry, AFM, piezoelectric microcantilever or SPR (Zhavnerko and $\mathrm{Ha}, 2004$ ). However, getting all the elements to work is far more difficult than with DNA arrays. Analysis of nucleic acid interactions on DNA arrays is simple and streamlined, because nucleic acids have a characteristic and distinct complementary binding. In contrast, protein interaction is influenced by various factors including three-dimensional structure, chemical interaction and isoelectric points of proteins. Thus, it is essential to array specific adaptor molecules in preparing protein arrays.

\section{Fluorescence detection method}

Detection and quantification of proteins captured on 
arrays require an additional technique. Fluorescence detection method has been widely used, because it is a simple and extremely sensitive method, and provides a high resolution (Stears et al., 2003; Zhu and Snyder, 2003). The method is also compatible with standard DNA array scanners. MacBeath and Schreiber (2000) arrayed proteins on chemically modified glass slides by using a robot originally designed to prepare DNA arrays, then interacting protein $G$, p50 and FRB with their binding proteins, and analyzed by a standard DNA array scanner. This first report of protein arrays with over 10,000 spots on a small glass slide, stimulated development of protein array technologies. The first proteome array was reported by Snyder's group (Zhu et al., 2001). They cloned 5,800 open reading frames from yeast and purified their corresponding proteins as $\mathrm{N}$-terminal GST-His 6 double-tagged fusions. The proteins were printed onto slides and screened for their activities to interact with calmodulin and phospholipids including phosphatidylcholine and phosphoinositides. Recently, a highly sensitive protein array coated with a calixcrown derivative has been used for the study of integrin-extracellular matrix protein interactions by fluorescence detection (Lee et al., 2004). However, this method has disadvantages including heterogeneity of fluorescence labeling of proteins.

\section{Label-free detection method}

Because labeling proteins or biomolecules with fluorophores or other detection probes may result in the loss of their biological activity by conformational change, non-labeling methods are preferred as direct detection approaches including SELDI mass spectrometry, AFM and SPR (Zhu and Snyder, 2003). The SELDI mass spectrometry technique was adapted from the conventional matrix-assisted laser desorption/ionization (MALDI) mass spectrometry, which has been used for determination of purity and molecular weight of macromolecules, such as proteins (Griesser et al., 2004). The surface MALDI mass spectrometry is capable of desorbing adsorbed macromolecules from biomaterial surfaces and detecting their molecular ions with high resolution (Griesser et al., 2004). The mass spectrometry method is rapid, experimentally convenient, and overcomes limitations in mass resolution. However, this method has disadvantages, in which proteins tightly bound to the plate surface are not detectable, and proteins are not recovered after analysis.

An alternative to the fluorescence method is a sandwich assay, which utilizes two capture molecules such as antibodies that simultaneously bind a protein (Wilson and Nock, 2001). The sandwich method is highly specific because two molecules should simultaneously recognize the protein to produce signals. However, disadvantage of this method is that it requires two specific binding agents for each protein.

AFM method provides information of surface topological changes to identify captured proteins on protein arrays (Zhu and Snyder, 2003). Figure 1 shows the surface topology of tissue transglutaminase and transferrin that were immobilized onto the surfaces of metal ions. Metal ions were captured on the multilayer surface of two charged polyelectrolytes, poly(diallyldimethylammonium)chloride and poly(sodium 4-styrenesulfonate), which was prepared by the layer-by-layer method. Two proteins were well immobilized on the surface of cationic ions with a crystallized structure. Thus, AFM is able to monitor the changes in the topology of protein array surfaces that may not be provided by other methods. In addition, it is very useful to combine AFM method with other label-free method such as SPR method.

One promising method for analysis of protein arrays is SPR method, which is label-free and is capable of detecting and quantifying bound proteins onto arrays by using changes in the refractive index of the surface (McDonnell, 2001). An advantage of SPR method is that the method may be combined with other methods such as MALDI mass spectrometry and AFM to obtain additional information such as identification of captured proteins and surface topology of bound proteins on arrays. Detailed applications of SPR biosensors will be discussed at the later
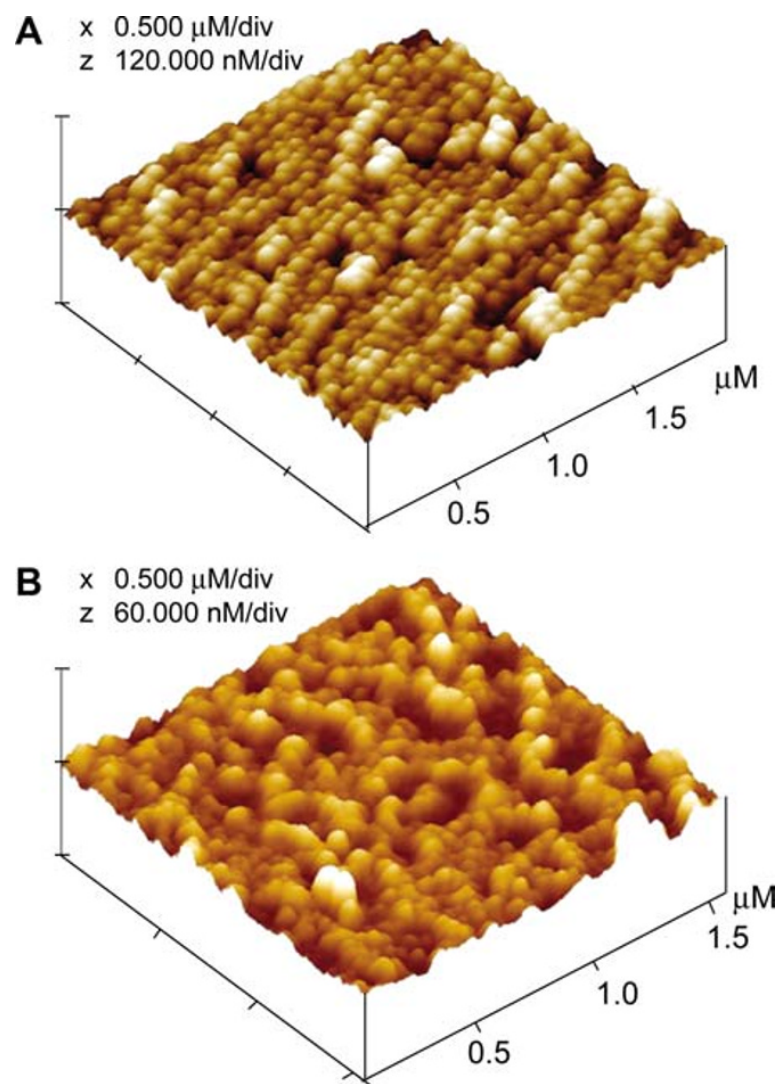

Figure 1. AFM images of tissue transglutaminase (A) and transferrin (B) on the surface of metal ions. Tissue transferase and transferrin were immobilized on the surface of $\mathrm{Zn}^{2+}(\mathrm{A})$ and $\mathrm{Fe}^{3+}(\mathrm{B})$, respectively, which were captured on the multilayer surface of (diallyidimethylammonium)chloride and poly(sodium 4-styrenesulfonate) and AFM images were obtained by the contact mode of Nanoscope Illa. 
part of this review.

\section{Two classes of protein arrays}

\section{Analytical protein arrays}

There are two general types of protein arrays for analyzing genomic sets of proteins; analytical and functional protein arrays. Analytical protein arrays are prepared by spotting proteome-specific ligands such as antibodies, nucleic acid aptamers or chemical probes on arrays, and used to monitor the expression level of proteins in parallel by applying protein extracts to the arrays (Phizicky et al., 2003; Zhu and Snyder, 2003). Analytical protein arrays have a potential for monitoring protein expression on a genome scale, protein profiling and clinical diagnosis. The most common form of analytical protein arrays is antibody (or antibody-mimic) arrays, in which antibodies are arrayed on a glass slide at high density. Detection of antibody-antigen interactions on arrays is usually performed by using labeled lysates (MacBeath and Schreiber, 2000; Zhu et al., 2001). Recently, the interaction between antibodies and antigens has been analyzed by spectral SPR biosensors (Yuk et al., $2004 \mathrm{a}$ ). The main problems with antibody arrays are the production of antibodies and the specificity of antibody-antigen interactions. Thus, the main challenge of these methods is producing capture molecules including antibodies that specifically identify target proteins (Zhu and Snyder, 2003).

In addition to antibody microarrays, there is another type of analytical protein array, which is used for profiling antibodies in a patient serum. This type of analytical protein array has been used to identify autoimmune diseases and allergens (Joos et al., 2000; Hiller et al., 2002). Joos et al. (2000) created a microarray-based immunoassay with 18 antigens to quantify autoantibodies in the sera of patients with autoimmune disease. The protein array technology has been applied to develop a miniaturized allergy test containing 94 purified allergen molecules (Hiller et al., 2002). The allergen microarray was used to determine and monitor allergic patients' IgE reactivity profiles to large numbers of disease-causing allergens in a single measurement.

\section{Functional protein arrays}

The second type of protein arrays is functional protein arrays, in which purified proteins are spotted on a solid surface and their activities are analyzed (Phizicky et al., 2003; Zhu and Snyder, 2003). Recently, a new technology for generation of protein arrays was reported by Ramachandran and his colleagues (2003). They produced protein arrays by printing complementary DNAs onto glass slides and translating proteins with a mammalian reticulocyte lysate. Epitope tags fused to the translated proteins allowed them to be immobilized in situ. The potential use of functional protein arrays has been shown by conducting enzyme assays to identify their downstream targets (MacBeath and Schreiber, 2000; Zhu et al., 2000). Zhu et al. (2000) identified substrates of 119 protein kinases from yeast using 17 different substrates and disposable nanowells in silicone elastomer sheets placed on top of glass slides. MacBeath and Schreiber (2000) further demonstrated the potential use of the arrays in the parallel biochemical analysis. The first protein array on a genomic scale has been shown by Zhu et al. (2001). In this report, they printed 5,800 proteins purified from yeast onto an array and identified new calmodulin- and phospholipid-binding proteins. The big challenge of the functional protein arrays is to produce proteins on a genomic scale. Many research groups have contributed tremendous efforts in development of high-throughput protein preparation methods (Zhu et al., 2001; Braun et al., 2002).

\section{Surface engineering for SPR biosensors}

Protein arrays are very powerful in analyzing functions of multiple proteins in a parallel format. However, proteins may undergo denaturation during the array procedure on a solid substrate and show non-specific binding in the analysis of multiple biomolecular interactions (Wilson and Nock, 2001; Zhavnerko and $\mathrm{Ha}, 2004)$. Thus, it is essential to develop methods to reduce denaturation and non-specific interaction in preparation and analysis of protein arrays.

\section{Physical adsorption}

Proteins can be arrayed onto solid supports by physical adsorption, covalent attachment, and oriented immobilization using streptavidin-coated surface or $\mathrm{Ni}^{2+}$-chelating surface (Wilson and Nock, 2001; Zhu et al., 2001; Zhavnerko and Ha, 2004). Physical adsorption is a reversible reaction and very easy to perform. Various kinds of polyelectrolytes have been applied to form monolayer or multilayer films by selfassembled monolayer method or layer-by-layer adsorption (Figure 2A), and proteins are immobilized onto charged surfaces by electrostatic interaction (Baba et al., 2000; Yi et al., 2003; Zhavnerko and $\mathrm{Ha}, 2004)$. However, protein interactions on the surface of solid substrates have physical natures, and interaction between proteins and a base monolayer can be easily influenced by their environment, such as surface charge, isoelectric points of proteins, and buffer $\mathrm{pH}$. Thus, proteins are easily immobilized onto solid surfaces by physical adsorption, but the immobilized proteins can be susceptible to the reduction of biological activity by an inappropriate orientation caused by physical adsorption. 
A

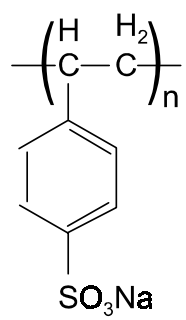

(1)<smiles>CC(C)(C)C1C[N+](C)(C)CC1C(C)(C)C</smiles>

(2)<smiles>CC(C)(C)CCCCCC(C)(C)CCl</smiles>

(3)

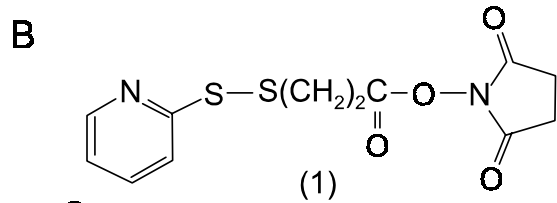

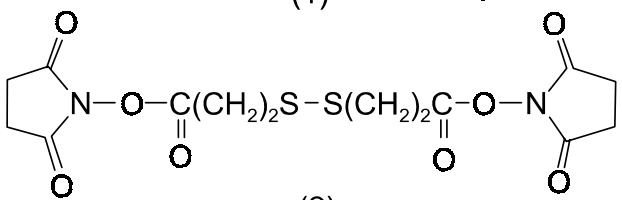

(2)

$$
\mathrm{H}_{2} \mathrm{~N}-\left(\mathrm{CH}_{2}\right)_{3}-\mathrm{Si}\left(\mathrm{OC}_{2} \mathrm{H}_{5}\right)_{3}
$$

(3)<smiles>CC(=O)ON1C(=O)CCC1=O</smiles>

(4)

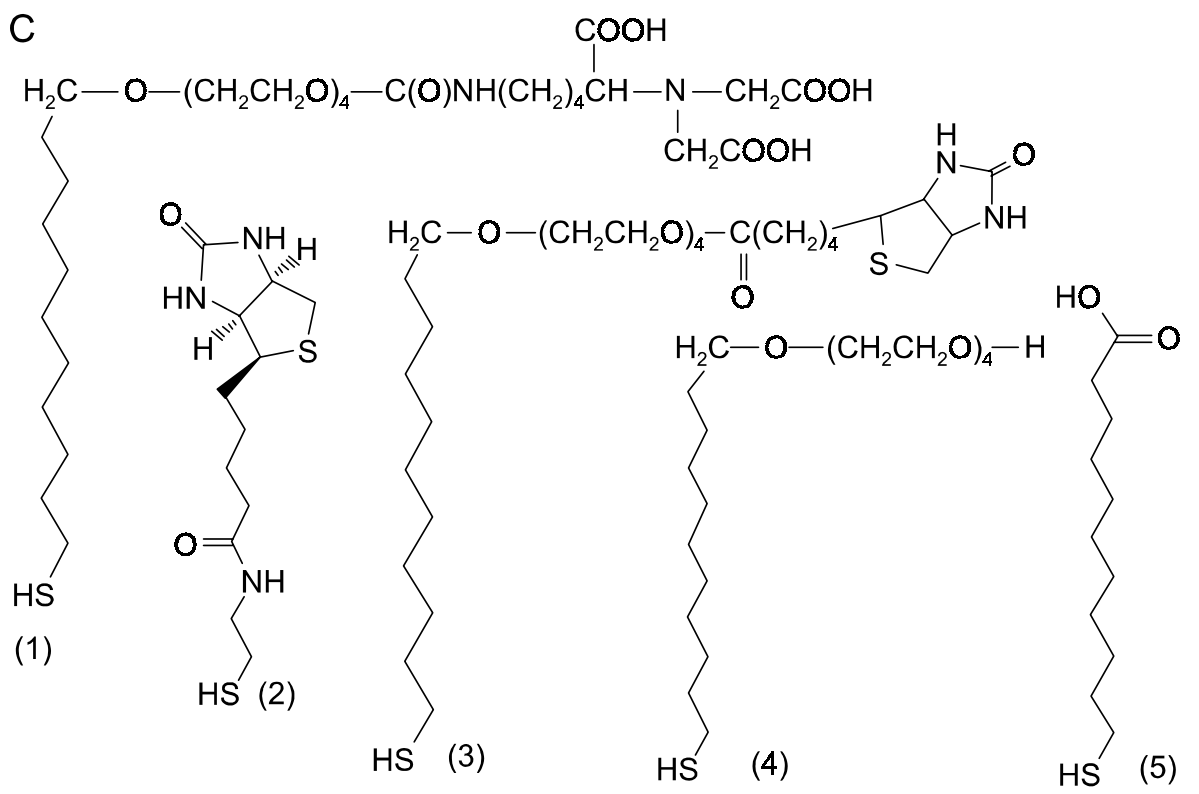

Figure 2. Molecules for surface engineering of protein arrays. (A) Polyelectrolytes for physical adsorption. (1) poly(diallyldimethylammonium)chloride, (2) poly(sodium 4-styrenesulfonate), (3) polyallylamine hydrochloride; (B) Molecules for covalent modification, (1) 3-(2-pyridyldithio)propionic acid N-hydroxysuccinimide ester, (2) di(N-succinimidyl)-3,3'-dithiodipropionate, (3) aminopropyltriethoxysilane, (4) 4-maleidobutyric acid $\mathrm{N}$-hydroxysuccinimide ester; (C) organothiol molecules for the formation of self-assembled monolayer on gold surface, (1) nitrilotriacetic acid-terminated tetra(ethylene glycol) undecylthiol, (2) 5-(biotinamido)ethanethiol, (3) biotin-capped tetra(ethylene glycol) undecanoate, (4) 1-mercapto-11-undecyl tetra(ethylene glycol), (5) 11-merHS (5) captoundecanoic acid.

\section{Covalent adsorption}

More specific and stronger attachment of proteins can be obtained by covalent modification. Covalent modification requires a bifunctional cross-linker, which has one functional group that reacts with a base support, and another group that interacts with an active group of proteins (Zhu and Snyder, 2003) (Figrue 2B). Silane coupling reagents are frequently used as linkers to modify glass, quartz and silicon surfaces, because they can withstand harsh solvents and do not interfere optical properties of quartz substrate (MacBeath and Schreiber, 2000; Zhavnerko and $\mathrm{Ha}$, 2004). When gold-coated glass surface is used to immobilize proteins, a bifunctional thio-alkylene, such as mercaptoundecanoic acid, is usually used to form a self-assembled monolayer on the gold surface (Figrue 2C) (Yuk et al., 2004a). The advantage of goldcoated glass surface is that the dynamics of molecular interactions can be monitored by SPR spectroscopy (Yuk et al., 2003). However, immobilization by covalent modification may results in the random 
orientation of biomolecules and loss of their biological activities.

\section{Oriented im mobilization}

Orientated immobilization of proteins or antibodies is the most important issue in the preparation of protein arrays to reduce non-specific interactions and to increase the sensitivity of biosensors. There have been a number of coupling methods for oriented immobilization of biomolecules, including immobilization of biotinylated biomolecules onto streptavidin-coated surfaces (Wilson and Nock, 2001), immobilization of his-tagged proteins onto $\mathrm{Ni}^{2+}$-chelating surfaces (Zhu et al., 2001), and immobilization of GST-fusion proteins onto GSH surfaces (Wilson and Nock, 2001; Zhu et al., 2001; Zhavnerko and $\mathrm{Ha}, 2004$ ). In addition, antibodies can be arrayed by using protein $A$ or $G$ from Staphylococcus that specifically bind to the Fc region of antibodies (Lee et al., 2003). Avidinbiotin coupling is a prominent reaction to orient proteins and antibodies on solid surfaces in preparing protein and antibody arrays, respectively. However, it is necessary to modify solid surfaces with streptavidin by using additional bifunctional monolayers to immobilize biotinylated proteins or antibodies such as 5-(biotinamido)ethanethiol (Figure 2c).

\section{Applications of SPR biosensors for proteome researches}

SPR is an electromagnetic phenomenon in which an evanescent wave excites the charge density oscillation along the metal/dielectric interface (Yuk et al., 2004a). SPR method is an optical technique that uses the evanescent wave to measure changes in refractive index on the sensor surface (McDonell, 2001). Interactions of proteins or analytes with capture molecules on a sensor surface result in the changes in refractive index. Biomolecular interactions have been intensively monitored by two types of SPR sensors; angular and spectral SPR biosensors (Homola et al., 1999; Yuk et al., 2005). Angular SPR biosensors are based on the angular interrogation and analyze protein interactions by scanning incidence angles at a constant wavelength. Spectral SPR biosensors are based on the wavelength interrogation and scan wavelengths at a constant incidence angle to analyze biomolecular interactions. However, most of researches have been focused on in situ analysis of singular biomolecular interactions. Recently, a number of research groups have reported a potential use of SPR biosensors for high-throughput analysis of protein interactions in a parallel format (Myszka and Rich, 2000; O'Brien et al., 2001; Chung et al., 2004; Yuk et al., 2004a; 2005).

\section{Analysis of protein interactions by SPR biosensors}

\section{SPR imaging}

As previously discussed, SPR biosensors have various advantages including real-time measurement of molecular interactions without labeling and the simple optical system for the device. Thus, there have been numerous efforts to apply the SPR biosensors to the proteome researches (Myszka and Rich, 2000; O'Brien et al., 2001; Chung et al., 2004; Yuk et al., 2004a; 2005). Analysis of multiple biomolecular interactions on arrays has been tried by a SPR imaging technology. SPR imaging permits monitoring of biomolecular interactions by detecting the intensity change of reflected lights resulting from changes in the refractive index on the gold surface. SPR imaging previously has been used to study biopolymer adsorption onto patterned surfaces and is an ideal way to monitor the binding of proteins onto arrays in situ as well as ex situ (Rothenhausler and Knoll, 1988; Brockman et al., 1999). Corn's group has shown an application of SPR imaging method in monitoring the adsorption of single-stranded DNA binding protein to an oligonucleotide array (Brockman et al., 1999). Recently, expression of affinity-tagged proteins in Escherichia coli was monitored in a high-throughput manner by SPR imaging (Jung et al., 2004). They spotted three proteins, hexahistidine-tagged human growth factors, glutathione S-transferase-tagged human interleukin- 6 and maltose-binding protein-tagged human interleukin-6, onto gold coated glass slides modified with $\mathrm{Ni}(\mathrm{II})$-iminodiacetate, glutathione and cyclodextran, respectively, and then adsorption of proteins were analyzed by SPR imaging. However, SPR spectrum may not horizontally move or may be complicatedly moved by adsorption of biomolecules, which results in the fluctuation of SPR intensity that is the key parameter for SPR imaging.

\section{SPR spectroscopic imaging}

Another approach for monitoring protein interactions on arrays is SPR spectroscopic imaging, which is based on the combined technology of position automation and SPR spectroscopy. Recently, Ha's group has reported a spectral SPR biosensors based on wavelength interrogation to analyze protein arrays in situ and ex situ by spectroscopic imaging based on line-scanning and whole-scanning modes (Yi et al., 2003; Yuk et al., 2003; 2004a; b; 2005; Zhavnerko and $\mathrm{Ha}, 2004)$. SPR spectroscopic imaging is different from SPR imaging, in that the former uses the shift of SPR wavelength, but the latter does that of SPR intensity. Thus, SPR spectroscopic imaging may provide more accurate information than SPR imaging method. Analysis of protein arrays by a wholescanning mode can be performed by scanning the whole surface of protein arrays on an $x-y$ stage, and by constructing 2- or 3-dimensional images by using the subsequently obtained SPR wavelength data 
A

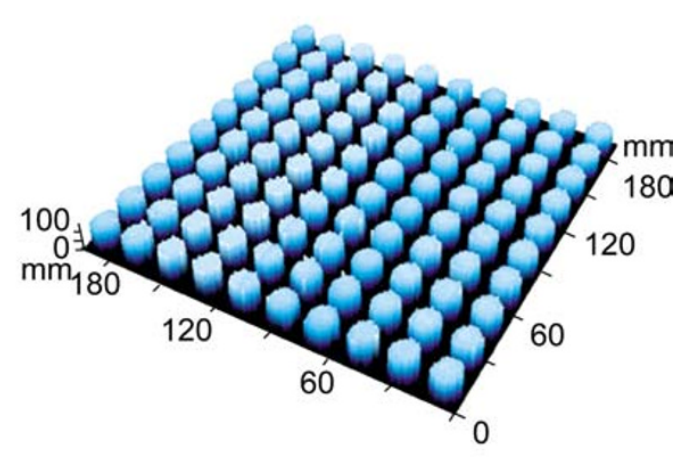

B

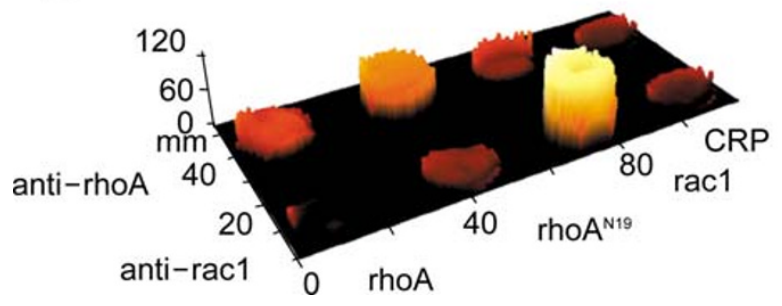

Figure 3. Analysis of a protein array (a) and protein interactions between small G-proteins and their antibodies (b) by whole-scanning mode of a spectral SPR biosensor. (a) A protein array was modified with polyelectrolytes by layer-by-layer method and analyzed by a spectral SPR biosensor. (b) Three small G-proteins and C-reactive protein were immobilized onto a protein array modified with a mixed thiol layer of 11-mercaptoundecanoic acid and mercaptohexanol, and their interactions with monoclonal antibodies against rhoA and rac1 were analyzed by a spectral SPR biosensor.

(Zhavnerko and $\mathrm{Ha}, 2004)$. Figure 3 shows an example of protein array analysis by the whole-scanning mode of spectral SPR biosensors. In Figure 3A, a protein array was modified with polyelectrolytes by layer-by-layer method, and the surface was analyzed by a spectral SPR biosensor. In addition, antibodyantigen interactions on arrays were also analyzed by the SPR biosensor (Figure 3B). Three G-proteins such as rhoA, rhoA ${ }^{\mathrm{N} 19}$, and rac1, and $\mathrm{C}$-reactive protein were immobilized onto the surface of a protein array modified with a mixed thiol, and incubated with two monoclonal antibodies against rhoA and rac1. Then, the array was analyzed by the whole-scanning mode of a spectral SPR sensor. The whole-scanning method can provide detailed information on the quantity and distribution of proteins adsorbed onto the protein array. However, the whole-scanning method takes a long time to finish scanning since the whole surface area of protein chip should be scanned by moving an $x-y$ stage.

Alternative approach to the whole-scanning mode is a line-scanning mode (Yuk et al., 2004a; 2005). Yuk et al. (2004a) have shown analysis of antibodyantigen interactions on protein arrays by the linescanning analysis of SPR spectroscopic imaging. They scanned protein arrays along the central lines of array spots by moving an $x-y$ stage, and the amount of protein bound to the protein arrays are
A
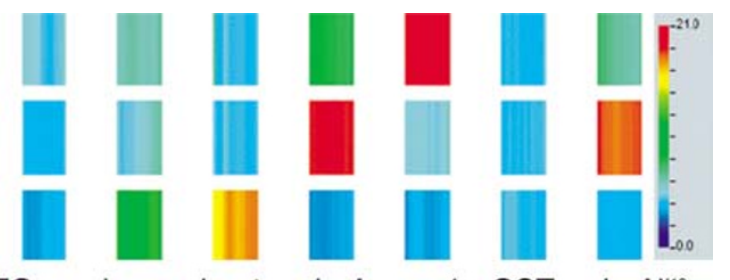

TGase hemo hapto rhoA rac1 GST rhoA ${ }^{\text {N19 }}$

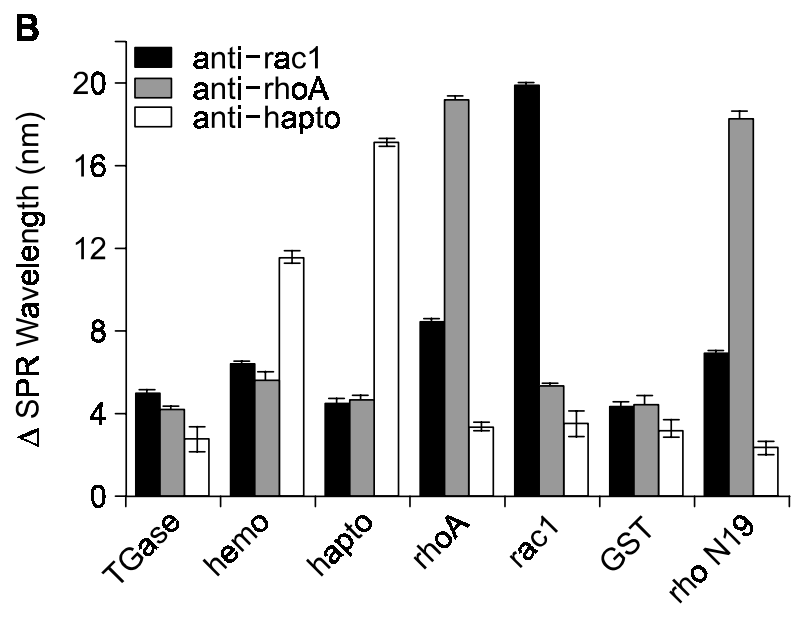

Figure 4. Analysis of antigen-antibody interactions on protein arrays by line-scanning mode of a spectral SPR biosensor. (A) Protein arrays prepared by immobilizing tissue transglutaminase (TGase), hemoglobin (hemo), haptoglobin (hapto), rhoA, rac1, GST and RhoA ${ }^{\mathrm{N} 19}$ on the mixed thiol, and incubated with antibodies against rhoA (top lane), rac1 (middle lane) and haptoglobin (bottom lane). Then, the protein arrays were analyzed by the line-scanning mode of a spectral SPR biosensor. (B) Averages of SPR wavelength shifts.

shown by a color spectrum. Figure 4 shows a result of antibody-antigen interactions on a protein array. Seven different proteins, such as tissue transglutaminase, hemoglobin, haptoglobin, rhoA, rac1, GST and $\operatorname{rho}^{\mathrm{N} 19}$, were immobilized on the array surfaces and then their interactions with three antibodies against rhoA, rac1 and haptoglobin were analyzed by the line-scanning mode of the SPR biosensor. This analysis provides detailed characteristics of molecular interactions on the protein arrays. It was also reported that the sensitivity of an ex situ spectral SPR biosensors was about twice as high as that of an in situ spectral SPR biosensor for the same resonance wavelength range (Yuk et al., 2004b). Thus, spectroscopic imaging by ex situ spectral SPR biosensors has the strong potential for high-throughput screening of proteomes.

\section{SPR spectroscopy}

Automation and sensitivity improvement of SPR biosensors may permit large-scale screening of proteins and detection of small molecules for drug discovery effort (McDonnell, 2001). Adamczyk et al. (2000) have used an angular SPR sensor to monitor immobili- 
zation of thyroxin (T4) analogs onto anti-T4 Fab fragment. The use of SPR biosensors in the discovery and development of small molecule drugs was reviewed by Myszka and Rich (2000). They described a prototype microarray chip that has 64 spots of serum albumin immobilized within one flow cell of a BIACore chip. Proteins were immobilized using a standard amine-coupling method via an ink-jet technology.

\section{Other applications of SPR biosensors}

Application of SPR biosensors is powerful when the biosensors are used in tandem with AFM or mass spectrometry. Integration of SPR biosensors with mass spectrometry has been reported by Williams and Addona (2000). In this report, proteins and peptides were captured on the surfaces of SPR biosensors and identified using mass spectrometry. Combination of SPR and mass spectrometry is a rapid and powerful approach for identifying captured biomolecules from complex mixtures of components, and thus can provide a potential tool for large-scale analyses of proteomes. The SPR biosensors are also highly complementary to an imaging technique of AFM. AFM is able to provide information on the changes of topology and thickness of protein layers immobilized on the surfaces of protein arrays (Figure 1) (Green et al., 2000).

In addition, SPR biosensors have been applied to monitor immobilization of bacteria on antibody arrays, serum antibodies against bacteria, and conformation changes of proteins (Sota et al., 1998; Oh et al., 2004). SPR biosensors have been used to detect pathogens such as Escherichia coli, Salmonella typhimurium, Legionella pneumophila and Yersinia enterocolitica (Oh et al., 2004). Conformational change of a genetically altered dihydrofolate reductase from Escherichia coli is also investigated by the changes in SPR signal (Sota et al., 1998).

\section{Conclusions}

Recent demands in the methodology development in proteomics has brought a significant advancement in the sensitivity and reliability in probing the structural and functional properties of minuscule levels of proteins and identification of protein markers for diagnosis and drug screening. Protein array technology has been applied to proteomics for high-throughput screening of protein interactions on a proteomic scale. Various techniques such as fluorescence, atomic force microscopy and SPR biosensors have been used to analyze protein arrays. Fluorescence detection method is widely used, since it is a simple and extremely sensitive and compatible with DNA array technology. However, disadvantages of this method are that it requires labeling of fluorophores that may result in the loss of protein activity and that the fluorescence labeling is heterogeneous. One of the most prominent label-free methods for protein array analysis is SPR biosensor. Protein interactions on arrays have been successfully investigated by two methods of SPR biosensors, SPR imaging and SPR spectroscopic imaging, which use resonance intensity and wavelength, respectively. In addition, SPR biosensors are compatible with other technologies such as atomic force microscopy and mass spectroscopy. Thus, SPR biosensors have a strong potential for high-throughput analysis of proteomes.

\section{Acknowledgement}

This work was supported in part by a grant of the Korea Health 21 R\&D Project, Ministry of Health \& Welfare, Republic of Korea (02-PJ10-PG6-GP01-0002).

\section{References}

Adamczyk M, Moore JA, Yu Z. Application of surface plasmon resonance toward studies of low-molecular-weight antigen-antibody binding interactions. Methods 2000;20:31928

Aebersold R, Mann M. Mass spectrometry-based proteomics. Nature 2003;422:198-207

Anderson NL, Anderson NG. The human plasma proteome. Mol. Cell. Proteomics 2002;1:845-67

Baba A, Kaneko F, Advincula RC. Polyelectrolyte adsorption processes characterized in situ using quartz crystal microbalance technique: alternate adsorption properties in ultrathin polymer films. Colloids Surf 2000;173:39-49

Braun $P$, Hu Y, Shen B, Halleck A, Koundinya M, Harlow E, LaBaer J. Proteome-scale purification of human proteins from bacteria. Proc Natl Acad Sci USA 2002;99:2654-9

Brockman JM, Frutos AG, Corn RM. A multiple chemical modification procedure to create DNA arrays on gold surfaces for the study of protein-DNA interactions with surface plasmon resonance imaging. J Am Chem Soc 1999;121: 8044-51

Durr E, Yu J, Krasinska KM, Carver LA, Yates JR, Testa JE, Oh P, Schnitzer JE. Direct proteomic mapping of the lung microvascular endothelial cell surface in vivo and in cell culture. Nature Biotech 2004;22:985-92

Gerson D. Probing the proteome. Nature 2003;424:581-7

Giot L, Bader JS, Brouwer C, Chaudhuri A, Kuang B, Li Y, Hao YL, Ooi CE, Godwin B, Vitols E, Vijayadamodar G, Pochart $P$, Machineni $H$, Welsh $M$, Kong $Y$, Zerhusen $B$, Malcolm R, Varrone Z, Collis A, Minto M, Burgess $S$, McDaniel L, Stimpson E, Spriggs F, Williams J, Neurath K, loime N, Agee M, Voss E, Furtak K, Renzulli R, Aanensen $N$, Carrolla S, Bickelhaupt E, Lazovatsky $Y$, DaSilva A, Zhong J, Stanyon CA, Finley RL Jr, White KP, Braverman $M$, Jarvie $T$, Gold $S$, Leach $M$, Knight J, Shimkets RA, McKenna MP, Chant J, Rothberg JM. A protein interaction map of Drosophila melanogaster. Science 2003;302:172736 
Green RJ, Frazier RA. Shakesheff, KM, Davis MC, Roberts, CJ, Tendler SJB. Surface plasmon resonance analysis of dynamic biological interactions with biomaterials. Biomaterials 2000;21:1823-35

Griesser HJ, Kingshott $P$, McArthur SL, McLean KM, Kinsel GR, Timmons RB. Surface-MALDI mass spectroscopy in biomaterials research. Biomaterials 2004;25:4861-75

Hanash S. Disease proteomics. Nature 2003;422:226-32

Hiller R, Laffer S, Harwanegg C, Huber M, Schmidt WM, Twardosz A, Barletta B, Becker WM, Blaser K, Breiteneder $H$, Chapman M, Crameri R, Duchene M, Ferreira F, Fiebig $\mathrm{H}$, Hoffmann-Sommergruber K, King TP, Kleber-Janke T, Kurup VP, Lehrer SB, Lidholm J, Muller U, Pini C, Reese G, Scheiner O, Scheynius A, Shen HD, Spitzauer S, Suck R, Swoboda I, Thomas W, Tinghino R, Van Hage-Hamsten M, Virtanen T, Kraft D, Muller MW, Valenta R. Microarrayed allergen molecules: diagnostic gatekeepers for allergy treatment. FASEB J 2002;16:414-6

Homola J, Yee SS, Gauglitz G. Surface plasmon resonance sensors: review. Sens. Acuators B 1999;54:3-15

Jongerius-Gortemaker, BGM, Goverde RLJ, van Knapen F, Berwerff AA. Surface plasmon resonance (BIACORE) detection of serum antibodies against Salmonella enteritidis and Salmonella typhimurium. J Immunol Methods 2002;266:3344

Joos TO, Schrenk M, Hopfl P, Kroger K, Chowdhury U, Stoll $D$, Schorner D, Durr M, Herick K, Rupp S, Sohn K, Hammerle H.. A microarray enzyme- linked immunosorbent assay for autoimmune diagnostics. Electrophoresis 2000;21: 2641-50

Jung JM, Shin YB, Kim MG, Ro HS, Jung HT, Chung BH. A fusion protein expression analysis using surface plasmon resonance imaging. Anal Biochem 2004;330:251-6

Lee W, Oh BK, Min Bae Y, Paek SH, Hong Lee W, Choi JW. Fabrication of self-assembled protein $A$ monolayer and its application as an immunosensor. Biosens Bioelectron 2003; 19:185-92

Lee Y, Lee EK, Cho YW, Matsui T, Kang IC, Kim TS, Han $\mathrm{MH}$. ProteoChip: a highly sensitive protein microarray prepared by a novel method of protein immobilization for application of protein-protein interaction studies. Proteomics 2003;3:2289-304

Liedberg B, Nylander C, Lundstrom I. Surface plasmon resonance for gas detection and biosensing. Sensors and Actuators 1983;4:299-304

MacBeath G, Schreiber SL. Printing proteins as microarrays for high-throughput function determination. Science 2000;289: 1760-3

McDonnell JM. Surface plasmon resonance: towards an understanding of the mechanism of biological molecular recognition. Curr Opin Chem Biol 2001;5:572-7

Myszka DG, Rich RL. Imprementing surface plasmon resonance biosensors in drug discovery. Pharm Sci Tech Today 2000;3:310-7

O'Brien MJ, Perez-Luna VH, Brueck SRJ, Lopez GP. A surface plasmon resonance based on spectroscopic imaging. Biosens Bioelecton 2001;16:97-108
Oh BK, Kim YK, park KW, Lee WH, Choi JW. Surface plasmon resonance immunosensor for the detection of Salmonella typhimurium. Biosens Bioelectron 2004;19:1497-504

Oh BK, Lee W, Chun BS, Bae YM, Lee WH, Choi JW. The fabrication of protein chip based on surface plasmon resonance for detection of pathogens. Biosens Bioelectron 2005;20:1847-50

Phizicky E, Bastiaens PI, Zhu H, Snyder M, Fields S. Protein analysis on a proteomic scale. Nature 2003;422:208-15

Ramachandran N, Hainsworth E, Bhullar B, Eisenstein S, Rosen B, Lau AY, Walter JC, LaBaer J. Self-assembling protein microarrays. Science 2004;305:86-90

Rothenhausler B, Knoll W. Surface-plasmon microscopy. Nature 1998;332:615-7

Service RF. Searching for recipes for protein chips. Science $2001 ; 294: 2080-2$

Simpson RJ, Dorow DS. Cancer proteomics: from signaling networks to tumor markers. Trends Biotechnol 2001;19:S40S48

Sota $\mathrm{H}$, Hasegawa $\mathrm{Y}$. Detection of conformational changes in an immobilized protein using surface plasmon resonance. Anal Chem 1998;70:2019-24

Stears RL, Martinsky T, Schena M. Trends in microarray analysis. Nature Med 2003;9:140-5

Tyers M, Mann M. From genomics to proteomics. Nature 2003;422:193-7

Williams C, Addona TA. The integration of SPR biosensors with mass spectrometry: possible applications for proteome analysis. Trends Biotech. 2000;18:45-8

Wilson D, Nock S. Functional protein microarrays, Curr Opion Chem Biol 2001;6:81-5

Yan W, Lee H, Deutsch EW, Lazaro CA, Tang W, Chen E, Fausto N, Katze MG, Aebersold R. A dataset of human liver proteins identified by protein profiling via isotope coded affinity tag (ICAT) and tandem mass spectrometry. Mol. Cell. Proteomics 2004;3:1039-41

Yi SJ, Yuk JS, Jung SH, Zhavnerko GK, Kim YM, Ha KS. Immobilization on charged arrays studied with a surface plamson resonance wavelength-shift sensor. Mol Cells 2003; 15:333-40

Yuk J, Jung JW, Jung SH, Han JA, Kim YM, Ha KS. Sensitivity of ex situ and in situ spectral surface plasmon resonance sensors in the analysis of protein arrays. Biosens. Bioelectron. in press 2005

Yuk JS, Yi SJ, Lee HG, Kim YM, Ha KS. Characterization of surface plasmon resonance wavelength by changes of protein concentration on protein chips. Sens. Actuators B 2003;94:161-4

Yuk JS, Jung JW, Jung SH, Hong D, Han JA, Kim YM, Ha KS. Analysis of protein interactions on protein arrays by a wavelength interrogation-based surface plasmon resonance biosensor. Proteomics 2004a;4:3468-76

Yuk JS, Yi SJ, Han JA, Kim YM, Ha KS. SPR intensity in ex situ analysis of protein arrays by a wavelength interrogation-based SPR sensor. Jap J Apply Phys 2004b;43: 
$2756-60$

Zhavnerko G, Ha KS. Biosensor applications: surface engineering. In: Encyclopedia of Nanoscience and Nanotechnology. (Schwarz JA, Contescu C, Putyera K, eds), Marcel Dekker 2004;351-60

Zhu H, Bilgin M, Bangham R, Hall D, Casamayor A, Bertone $P$, Lan N, Jansen R, Bidlingmaier $S$, Houfek $T$, Mitchell $T$, Miller P, Dean RA, Gerstein M, Snyder M. Global analysis of protein activities using proteome chips. Science 2001;293: 2101-5

Zhu $\mathrm{H}$, Klemic JF, Chang S, Bertone $\mathrm{P}$, Casamayor $\mathrm{A}$, Klemic KG, Smith D, Gerstein M, Reed MA, Snyder M. Analysis of yeast protein kinases using protein chips. Nature Genet 2000;26:283-9

Zhu H, Snyder M. Protein chip technology. Curr Opin Chem Biol 2003;7:55-63 